LBNL - 60162

\title{
Sorbent-Based Gas Phase Air Cleaning for VOCs in Commercial Buildings
}

\author{
William J. Fisk \\ Environmental Energy Technologies Division \\ Indoor Environment Department \\ Lawrence Berkeley National Laboratory \\ Berkeley, CA
}

May 2006

This work was supported by the Assistant Secretary for Energy Efficiency and Renewable Energy, Building Technologies Program of the U.S. Department of Energy under contract DEAC02-05CH11231. 


\section{SORBENT-BASED GAS PHASE AIR CLEANING FOR VOCS IN COMMERCIAL BUILDINGS}

William J Fisk

Indoor Environment Department

Lawrence Berkeley National Laboratory

Berkeley, CA

May 15, 2006

\section{ABSTRACT}

This paper provides a review of current knowledge about the suitability of sorbent-based air cleaning for removing volatile organic compounds (VOCs) from the air in commercial buildings as needed to enable reductions in ventilation rates and associated energy savings. The fundamental principles of sorbent air cleaning are introduced, criteria are suggested for sorbent systems that can counteract indoor VOC concentration increases from reduced ventilation, major findings from research on sorbent performance for this application are summarized, novel sorbent technologies are described, and related priority research needs are identified. Major conclusions include: sorbent systems can remove a broad range of VOCs with moderate to high efficiency, sorbent technologies perform effectively when challenged with VOCs at the low concentrations present indoors, and there is a large uncertainty about the lifetime and associated costs of sorbent air cleaning systems when used in commercial buildings for indoor VOC control. Suggested priority research includes: experiments to determine sorbent system VOC removal efficiencies and lifetimes considering the broad range and low concentration of VOCs indoors; evaluations of in-situ regeneration of sorbents; and an updated analysis of the cost of sorbent air cleaning relative to the cost of ventilation.

\section{INTRODUCTION}

The US Department of Energy (DOE) and other energy agencies seek to reduce the consumption of energy for thermally conditioning the outdoor ventilation air provided to buildings. Ventilation is provided in buildings to maintain acceptable indoor concentrations of indoorgenerated air pollutants. In commercial buildings, the important indoor generated air pollutants are primarily particles, including bioaerosols, and volatile and semi-volatile organic compounds (VOCs). These buildings usually have weak indoor sources of inorganic gaseous pollutants such as carbon monoxide, nitrogen dioxide, and ozone ${ }^{1}$. In addition, commercial buildings normally have low concentrations of radon. Consequently, in commercial buildings the need to maintain acceptable indoor concentrations of indoor generated particles and VOCs determines the minimum acceptable rates of ventilation.

Indoor pollutant source control and air cleaning are two approaches with the potential for reducing the amount of ventilation that is needed to maintain acceptable indoor concentrations of

\footnotetext{
${ }^{1}$ Carbon dioxide is emitted indoors from the respiration of people; and carbon dioxide concentrations must be maintained at acceptable levels, e.g., below 5000 ppm, however, large decreases in ventilation rates are possible before carbon dioxide increases to levels of concern.
} 
indoor generated particles and VOCs. Practical air cleaning technologies for particles are available, typically consisting of fibrous filters installed in the supply air streams of heating, ventilating, and air conditioning (HVAC) systems. Except in the mildest of climates, the cost and energy use of efficient particle filtration is much smaller than the cost and energy use of an equivalent amount of particle removal by ventilation (Hodgson et al 2005, Appendix A). However, practical control of indoor-generated VOCs remains a challenge. VOC source control technologies involve selecting building materials, consumer products such as cleaning agents, and office equipment that have low emission rates of the VOCs that may have impacts on occupants. Source control measures can be highly effective and normally consumes no energy; thus, they should be considered a cornerstone for indoor VOC control. However, there are dozens of VOCs with a known or suspected potential to harm health or cause objectionable odors (Hodgson and Levin 2003) and large numbers of potential indoor VOC sources, not all of which have been characterized. Consequently, VOC source control presumably would be difficult to implement in large buildings and would requires ongoing efforts for a wide range of sources. Also, there are some sources, such as people and their personal care products, for which there are no practical control measures. Consequently, practical and effective air cleaning technologies for indoor-generated VOCs remains a high priority.

This document provides a brief introduction to the use of sorbents for air cleaning, suggests criteria for sorbent systems used as a substitute for a portion of building ventilation, reviews current information of the performance of sorbents for VOC removal, introduces new sorbent technologies that are the subject to current or recent research, and defines associated priority research needs. The paper focuses on sorbent systems installed in HVAC supply airstreams, not on smaller standalone air cleaners, as we believe that ducted systems are likely to be more efficient and more widely utilized in commercial buildings. The performance of solid-phase sorbents for controlling indoor concentrations of outdoor air pollutants such as ozone, sulfur dioxide, nitrogen oxides is not addressed.

\section{BRIEF INTRODUCTION TO SORBENT SYSTEMS}

\section{Physical adsorbents}

Any solid material will act, to at least a limited extent, as an adsorbent for VOCs; however, the sorbent media used most commonly for indoor VOC control are activated carbons, aluminas, and synthetic zeolites in granular form. Various polymers can also be manufactured with pores in desired size ranges to serve as adsorbers. All of these materials have a very high surface area per unit mass because they have extensive microscopic pores. For example, activated carbon - the most commonly used physical adsorbent -- has a surface area of 800 to $1500 \mathrm{~m}^{2} / \mathrm{g}$ primarily within pores with diameters less than 20 angstroms, i.e., 2 nanometers (Lui 1993). Most sorbents including activated carbon, have pores with a range of sizes. Synthetic zeolites, composed of oxides of aluminum, silicon, and sodium have uniform size pores as a consequence of their crystal structure; however, by varying the type and abundance of cations the pore size can be varied between 0.3 and 3.0 nanometers. Gaseous contaminants physically adsorb to the surfaces of sorbent media as a consequent van der Waals (nuclear attraction) forces. In addition, contaminants can condense within the small pores. The physical adsorption process is reversible; i.e., sorbed VOCs can be released and emitted back into air. The maximum amount 
of VOC that can be retained on the sorbent, often called the equilibrium capacity, increases with an increase in the gas phase VOC concentration. For a given temperature, the generally nonlinear curve of equilibrium-sorbed VOC mass (e.g., in gram of VOC per gram of sorbent) plotted versus the concentration of VOC in the gas phase that is in equilibrium with the sorbed VOC is called the adsorption isotherm. The equilibrium capacity of a sorbent, and thus the adsorption isotherm, varies with temperature, relative humidity, and among VOCs. The equilibrium capacity tends to be larger for less volatile, higher molecular weight VOCs.

\section{Chemisorbents}

Sorbent media may be chemically treated (impregnated) with an agent designed to react chemically with VOCs that are less easily removed by physical adsorption. Common examples are activated alumina or activated carbon impregnated with potassium or sodium permanganate which reacts with formaldehyde and several other compounds. The chemical reactions with the impregnants are irreversible; consequently, the reacted compound will not subsequently be released back into air. Gas phase filtration systems sometime use a mixture of chemisorbent treated and untreated sorbent media.

\section{Common methods of sorbent deployment}

Traditionally, trays filled with granular sorbent media are installed in the airstream to be cleaned - sometimes this deployment configuration is called a packed bed. Often, the sorbet grain size is 4 to 8 mesh (approximately $3 \mathrm{~mm}$ ) in diameter (Muller and Middlebrooks 2001). Smaller grains can lead to better mass transfer of the VOC from the air to the sorbent, but also results in higher airstream pressure drops. The trays holding the granular media are often approximately $2.54 \mathrm{~cm}$ (1 inch) thick. To reduce pressure drops, enable installation of a large mass of sorbent, and increase the residence time ${ }^{2}$ of VOC-laden air as it flows through the media, multiple trays are arranged in a zig-zag pattern (Figure 1) resembling the pleating of a fibrous filter. The mass of carbon deployed can be substantial; e.g., a system of granular sorbent in trays might contain 41 $\mathrm{kg}(90 \mathrm{lb})$ of activated carbon per $1 \mathrm{~m}^{3} / \mathrm{s}(2100 \mathrm{cfm})$ of airflow (Henschel 1998).

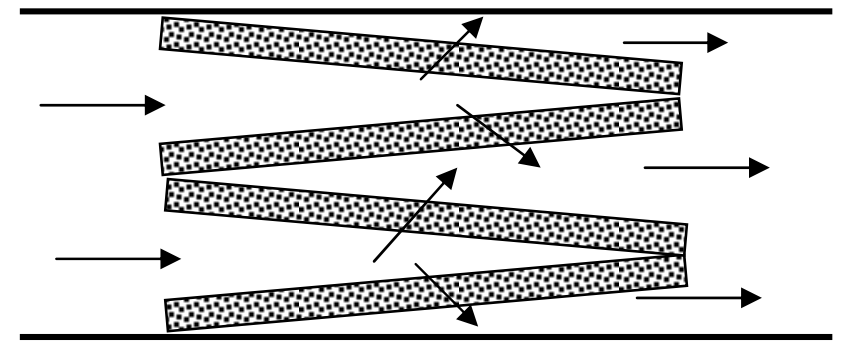

Figure 1. Schematic illustration of granular sorbent media in trays arranged in a zig-zag pattern. The arrows represent air flow directions.

Another sorbent deployment method, now quite common, is to integrate the sorbent media into a fibrous particle filter so that one product can be used for both particle and gas-phase filtration

\footnotetext{
${ }^{2}$ The nominal residence time equals the thickness of a sorbent bed divided by the face velocity of air entering the bed. Accounting for the porosity of the bed leads to a better estimate of actual residence time.
} 
(Muller 1993). For example, a slurry coating process may be used to apply a carbon powder on a fibrous filter media. Many particle filter manufacturers market such filters; however, the mass of sorbent deployed in the airstream may only be a few percent (sometimes $<1 \%$ ) of the sorbent in a system with trays filled with granular sorbent. Kinkead (1990) argued that the smaller sorbent particles increased VOC holding capacity; however, Muller (1993) and Middlebrook (2000) disagree.

Some manufacturers of sorbent media offer a media with grains of sorbent bonded onto a threedimensional non-woven fiber matrix not intended for particle filtration. With this method of sorbent deployment, the packing of sorbet grains is decoupled from sorbent grain size and smaller grains of sorbent may be used without encountering excessive airstream pressure drops. Figure 2 schematically illustrates how, in this type of non-woven media, the sorbent granules are spaced apart from one another. This in contrast with the dense granule spacing when granular media simply is poured into a tray. In non-woven media, a substantial quantity of sorbent can be practically deployed in an airstream. For example, a $61 \mathrm{~cm}$ by $61 \mathrm{~cm}$ by $30.5 \mathrm{~cm}$ deep (24 inch by 24 inch by 12 inch deep) filter with $7 \mathrm{~m}^{2}\left(75 \mathrm{ft}^{2}\right)$ of non-woven media used to treat $1 \mathrm{~m}^{3} / \mathrm{s}$ $(2100 \mathrm{cfm})$ of air might contain $3.5 \mathrm{~kg}(7.75 \mathrm{lb})$ of sorbent, while a system of trays of granular media of equivalent size with $2.5 \mathrm{~cm}$ (1 inch) thick trays would hold five to ten times more sorbent (Muller and Middlebrooks 2001). Still, per unit mass of sorbent deployed, airstream pressure drops can be reduced when the sorbent is bonded to a non-woven media. Middlebrooks (2000) compared pressure drops in three systems all with the same mass of granular activated carbon and a $1.0 \mathrm{~m} / \mathrm{s}(200 \mathrm{fpm})$ face velocity. The reported pressure drops were $38 \mathrm{~Pa}(0.15$ inch $\mathrm{H}_{2} 0$ ) in the system with 20 to 50 mesh carbon bonded to a pleated non-woven media, $640 \mathrm{~Pa}$ (2.6 in $\mathrm{H}_{2} \mathrm{O}$ ) with 20 to 50 mesh carbon in trays, and $75 \mathrm{~Pa}(0.3$ inch $\mathrm{H} 2 \mathrm{O})$ with seven-fold larger 4 by 8 mesh carbon in trays.

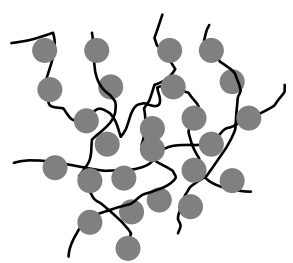

Figure 2. Schematic illustration of non-woven media with sorbent granules bonded to the fibers.

\section{Sorbent system performance metrics}

There are four primarily sorbent system performance metrics relevant to this paper.

- VOC removal efficiency, i.e., unity minus the ratio of downstream to upstream VOC concentration;

- Sorbent lifetime, i.e., the time elapsed between sorbent media installation and replacement;

- Airstream pressure drop as air flow through the sorbent system, which influences fan energy requirements; and

- Cost, e.g., total cost of sorbent air cleaning per unit delivery of VOC-free air.

HOW SORBENT SYSTEMS COULD REDUCE VENTILATION REQUIREMENTS 
Reducing the amount of outdoor air ventilation to save energy, without any compensating measures, will result in higher indoor concentrations of indoor-generated VOCs. Thus, a key question is as follows: can sorbent air cleaning maintain acceptable indoor VOC levels when ventilation rates are reduced? Unfortunately there is no broad agreement on the definition of "acceptable” indoor air quality or acceptable indoor air VOC levels. However, we can suggest criteria for determining if sorbent systems are acceptable, with respect to control of indoor VOC concentrations, as a substitute for a portion of building ventilation. To facilitate the discussion of these criteria, it is useful to define five categories of indoor VOCs: 1) outdoor-origin VOCs, i.e., indoor VOCs that originate in the outdoor air; 2) benign indoor-generated VOCs, i.e., indoorgenerated VOCs that are not suspected to be significant sources of adverse health effects or odors considering the concentrations found in non-industrial buildings; 3) odorous indoorgenerated VOCs; 4) irritant indoor-generated VOCs, 5) toxic indoor-generated VOCs; i.e., VOCs known or suspected to pose a risk of serious health effects such as cancer; and 6) reactive indoorgenerated VOCs, i.e., indoor-generated VOCs such as terpenes, that react with ozone and produce new VOCs and fine particles that are potentially harmful.

For the present discussion, we do not need to be concerned about the first two categories of VOCs. Reduced ventilation, even without VOC air cleaning, will not increase indoor concentrations of outdoor-origin VOCs, in fact, the indoor concentrations of some of these VOCs may be diminished with less ventilation. For the benign indoor-generated VOCs, the anticipated moderate reductions in building ventilation, e.g., 50\%, will not pose any risks, because the VOCs are benign at the expected concentrations. We also don't need to be concerned about increased indoor concentrations VOCs produced by reactions involving ozone if the sorbet system contains a substantial amount of activated carbon. Weschler et al (1992) and Gundel et al (2002) have shown that activated carbon can be highly effective in removing ozone for long periods. By reducing indoor concentrations of ozone, activated carbon systems should reduce the production of VOCs and fine particles via reactions involving ozone. This leaves three of the categories of VOCs to consider: odorous indoor-generated VOCs; irritating indoorgenerated VOCs, and toxic indoor-generated VOCs. The identities and odor and irritation potential of VOCs in the first two of these categories have been compiled and discussed by Hodgson and Levin (2003) and Wolkoff et al. (2006). The California EPA (2002) and the U.S. EPA (2000) have established lists of toxic or hazardous air contaminants that include most or all known toxic indoor-generated VOCs, and estimates of health risk versus concentration are available from the same organizations for these toxic air compounds.

We can now return to a description of suggested criteria for sorbent systems that are suitable for counteracting the VOC-concentration increases associated with reduced ventilation. One obvious criterion (called Criterion 1) for an acceptable sorbent system is as follows: for every single relevant odorous, irritating, or toxic indoor-generated VOC, the sorbent system and reduced rate of ventilation leads to an indoor VOC concentration that is less than or equal to the concentration expected indoors for a reference-case building that has more ventilation and no VOC air cleaning. To illustrate the VOC removal efficiency of the sorbent system necessary to meet this criterion, we assume that a user desires to reduce outdoor air supply by $50 \%$ to save energy - a goal of the U.S. Department of Energy’s Building Technology Program. Thus, we compare a reference building with a normal ventilation rate to a building with half as much 
ventilation plus a sorbent system for VOC removal. With a sorbent system installed in a supply airstream that is typically four parts recirculated indoor air and one part outdoor air, the sorbent system must have a VOC removal efficiency ${ }^{3}$ of only $12.5 \%$ to offset the decreased VOC removal resulting from a 50\% reduction in outdoor air supply. However, higher average efficiencies likely are required due to other factors. Importantly, the efficiency of VOC removal varies among VOCs, so the minimum efficiency for all of the important VOCs is $12.5 \%$. Also, as a sorbent becomes loaded with VOCs, or when temperature and humidity increase, VOC removal efficiency can decrease, so the worst-case VOC removal efficiency before the sorbent is replaced must equal $12.5 \%$. Infrequent short-term failures to meet this criterion should be considered acceptable, because the health consequences will be insignificant.

Criterion 1 may often be difficult or impractical to meet in practice because a few of the more volatile indoor-generated VOCs of concern are likely not readily removed by existing sorbents. However, two alternate criteria are proposed. Criterion 2 is as follows: the combination of the sorbent system with reduced ventilation, relative to the reference case, leads to indoor concentrations of relevant odorous, irritating, and toxic indoor-generated VOCs that are not increased, or the risks associated with any increased concentrations of these VOCs can be considered insignificant. Criterion 3 is similar, but focuses on the net impacts of all VOCs from all sources. Thus, Criterion 3 is as follows: the net risks of objectionable odors, irritation, and toxicity from all VOCs are lower with sorbent air cleaning and reduced ventilation than for the reference case of higher ventilation and no VOC air cleaning. Application of Criterion 3 credits the sorbent system for reducing indoor concentrations of outdoor-origin VOCs and for reducing indoor concentrations of many odorous, irritating, and toxic VOCs by more than the minimum amount (e.g., more than $12.5 \%$ for our example). While criteria 2 and 3 sound complicated, given existing data on odor thresholds, irritancy thresholds or potencies, and toxicity risks, it should be possible to use data from tests of sorbent systems and determine with a fair degree of confidence if these criteria are met. Also, analyses of sorbent data to determine if criterion 1 is met, is straightforward. It is not suggested that these criteria be applied on a building-bybuilding basis, rather they should be applied to data for some typical scenarios.

The temporal variability in sorbent system performance will complicate the application of any of these criteria. VOC removal efficiency will diminish after the sorbent becomes substantially loaded with sorbed VOCs. The need to maintain a minimum VOC removal efficiency and the decrease in sorbent efficiency over time lead to a maximum sorbent installation period or lifetime. The sorbent must be removed and replaced, or regenerated in-situ, when the efficiency falls or is predicted to fall below the minimum target value for the range of operating conditions. In laboratory studies, the breakthrough time is used as an indicator of sorbent lifetime. For example, a $50 \%$ breakthrough time is the elapsed period of sorbent use before the outlet VOC concentration reaches $50 \%$ of the inlet VOC concentration. For our example application where a user seeks to maintain the VOC removal efficiency above $12.5 \%$, the user would need to have estimates of the $87.5 \%$ breakthrough times for important VOCs. The lifetime of a sorbent system will, in general, increase in proportion to the amount of sorbent deployed. For physical adsorbents, increases in the humidity or temperature of air above standard conditions can diminish VOC removal efficiency. Also, an increase in the inlet concentration of a readily adsorbed VOC can decrease the efficiency of removal for a less readily adsorbed VOCs or even

\footnotetext{
${ }^{3}$ Calculated from a simple steady state mass balance equation.
} 
drive the less readily adsorbed VOC off the sorbent. In this latter case, the sorbent media might become an indoor VOC source leading to higher VOC concentrations than encountered if no sorbent system was used.

Due the complexity of these interacting factors, it will be difficult to design and determine when to replace a sorbent system if the target value of minimum VOC removal efficiency is far less than unity (e.g., 12.5\%). Consequently, it may often be preferable to use a sorbent system with a continuously high VOC removal efficiency that removes VOCs from only a portion of the supply airstream. With a suitable design, a sorbent could have a VOC removal efficiency near $100 \%$ for an extended period. Such a sorbent system would need to clean VOCs with $100 \%$ efficiency from only $8 \%(100 \% / 12.5 \%)$ of the supply airstream to remove $12.5 \%$ of the VOCs from the total supply airstream. This installation option would also reduce the amount of hardware required to hold the sorbent media and simplify the tracking of sorbet performance to determine when replacement is necessary; however, the complexity of supply duct system would increase and an extra small supply fan to overcome the pressure drop in the sorbent might be desirable.

\section{SUMMARY OF CURRENT KNOWLEDE ABOUT SORBENT PERFORMANCE}

\section{Types of research papers available}

Hundreds of papers on the performance of sorbent systems have been published. Most of these papers fall within one or more of the following categories:

- general descriptions of sorbent systems and their applications;

- description of sorbent test methods;

- laboratory studies of initial pollutant removal efficiencies;

- laboratory studies of breakthrough times when sorbents are challenged with one or two VOCs at concentrations ten to hundreds of times higher than experienced in buildings;

- development and use of theoretical models for predicting sorbent system efficiency and for predicting sorbent lifetime, e.g., extrapolating from lifetime with high inlet concentrations to lifetimes with more realistic inlet concentrations; and

- $\quad$ case studies of sorbent use.

This review identified only two studies that reported on long-term evaluations of sorbent systems installed in real buildings and that assessed performance for a range of VOCs. Also, only a few economic analyses of sorbents for commercial building IAQ applications were identified. In addition to published research literature, the web sites of sorbent manufacturers provide product data and some provide software to aide in sorbent system selection and estimation of performance.

\section{Laboratory tests of VOC removal with conventional media and associated modeling}

As examples of the many laboratory studies of sorbent performance, we provide brief reviews of Liu (1990), Van Osdell et al. (1996), and Muller (1993). Each of these studies investigated how sorbent characteristics and challenge-VOC characteristics affect VOC removal performance. The first two studies also investigated whether data from tests of sorbents conducted with very 
high inlet VOC concentrations can be used to estimate VOC removal efficiency or sorbent lifetime with the much lower inlet VOC concentrations encountered in practice ${ }^{4}$.

- Liu (1990) conducted experiments using columns with $2.54 \mathrm{~cm}$ (1 in) deep beds of granular activated carbon and airstream face velocities of $0.254 \mathrm{~m} / \mathrm{s}(47 \mathrm{fpm})$, which is typical of a face velocity used when trays of activated carbon are deployed in a zig-zag configuration. The nominal residence time in the carbon bed (bed depth divided by face velocity) was $0.1 \mathrm{~s}$, which is typical of a real installation. The airstream relative humidity was 50\%. He challenged the beds with either heptane or decane added to clean air. Inlet heptane concentrations were constant at 118, 15, 2.7 and $0.5 \mathrm{ppm}$ and inlet decane concentrations were constant at 15 and $0.2 \mathrm{ppm}$. Concentrations of heptane or decane in the air exiting the carbon beds were measured versus time until outlet concentrations equaled inlet concentrations after about 30 to 100 hours of testing. From the data, Lui calculated equibrium adsorption capacities. For example, with $118 \mathrm{ppm}$ of heptane in the inlet airstream, each gram of carbon retained $0.18 \mathrm{~g}$ of heptane (18\% equilibrium adsorption capacity), while with a $0.5 \mathrm{ppm}$ inlet heptane concentration, each gram of carbon retained $0.075 \mathrm{~g}$ of heptane. Initial VOC removal efficiencies were $95 \%$ to $97 \%$. From the data, Liu calculated how VOC removal efficiency varied with a normalized time defined as elapsed time divided by time elapsed until the carbon bed was fully saturated with the challenge VOC. The same curve of efficiency versus normalized time fit all of the experimental data, indicating that the useful sorbent lifetime can be predicted from data on equibrium sorbent capacity. Removal efficiency dropped to $50 \%$ with a normalized time of 0.5 and to approximately $15 \%$ with a normalized time of 0.8 . If we could apply such an efficiency curve to a real building application in which we needed to maintain a VOC removal efficiency above $12.5 \%$ to counteract a $50 \%$ decrease in outdoor air supply (see above), the carbon bed would need to be changed after an equilibrium time of approximately 0.8. However, it is unclear how well such a prediction applies for a real building application with dozens of VOCs and in the inlet airstream, all with time varying concentrations.

- Van Osdell et al (1996) conducted experiments similar to those of Liu (1990) but the carbon beds were challenged with five different ${ }^{5}$ VOCs (one VOC per experiment). Inlet concentrations per VOC ranged from $1100 \mathrm{ppm}$ to $0.1 \mathrm{ppm}$. They compared predictions and measurements of time elapsed before 10\% VOC breakthrough (i.e., time until removal efficiency dropped to 90\%). The inputs for the prediction included carbon bed physical characteristics, air flow rate, inlet VOC concentration, and the measured equilibrium capacity of the carbon for the VOC at the inlet air concentration. For three VOCs, the predicted and measured breakthrough time agreed reasonably well, i.e., the predicted time was always within 50\% of the measurement. For one VOC, the predictions were substantially less accurate, but not readily quantified given the log-log graphical presentation of the data.

\footnotetext{
${ }^{4}$ An ability to predict performance of sorbents with realistic VOC concentrations in the inlet stream based on the data obtained from tests performed using very high inlet VOC concentrations is very desirable, because sorption isotherm testing is quickly performed using high concentrations. Tests at realistic low inlet VOC concentrations can take months to perform.

${ }^{5} 1,1$ dicloroethane, hexane, methylethylketone, toluene, and decane
} 
- Muller (1993) compared the performance of traditional beds of granular activated carbon and/or activated alumina ${ }^{6}$ to the performance of carbon-impregnated filters (CIFs). CIFs typically have small carbon grains bound to a fibrous filter substrate and are generally intended for simultaneous particle removal and gas phase air cleaning. He challenged the filters with $100 \mathrm{ppm}$ of tolulene (and with $\mathrm{SO}_{2}$ as an example of an outdoor air contaminant) and measured the outlet concentration versus time. Air relative humidity was $50 \%$, temperature was $23{ }^{\circ} \mathrm{C}\left(74{ }^{\circ} \mathrm{F}\right)$ and the face velocity was $0.38 \mathrm{~m} / \mathrm{s}(75 \mathrm{ft} / \mathrm{min})$. The 19 CIFs contained 0.37 to $84 \mathrm{~g}$ of carbon per square meter of filter (4 to $\left.900 \mathrm{~g} / \mathrm{ft}^{2}\right)$ while the traditional media bed with only activated carbon contained $112 \mathrm{~g} / \mathrm{m}^{2}(1210$ $\mathrm{g} / \mathrm{ft}^{2}$ ). Initial tolulene removal efficiencies were 24 to $100 \%$ for CIFs and $82 \%$ for the reference bed of granular activated carbon. Calculations indicated that contact efficiencies (percent of pollutant reaching a carbon surface) were generally less than $60 \%$ for the CIFs and sometimes less than $10 \%$, while contact efficiency was $99 \%$ for the reference sorbent bed. There was a very clear increase in tolulene removal during the 30minute test with increased carbon content in the CIF. The main conclusion was that filter performance is determined primarily by residence time for air in the filter and the amount of carbon, contradicting a prior claim (Kinkead 1990) that the smaller particle grains on CIF filters can retain ten times as much VOC as the larger grains in traditional sorbentfilled trays.

These and other laboratory based studies supplemented by modeling lead to several conclusions about conventional sorbent systems. First, well-designed carbon based sorbent systems can have moderate to very high initial removal efficiencies for a range of VOCs, particularly for high molecular weight compounds (e.g., Van Osdell et al. 1996). More volatile VOCs (e.g., those with a lower boiling point) will often be removed less effectively by carbon (Liu 1993). The amount of VOC that can be retained on the carbon decreases with decreased inlet VOC concentration (Liu 1990, Liu 1993, Van Osdell et al. 1996) but carbon can still have a high VOC removal efficiency with part per billion VOC concentrations typical of those found in buildings (Graham and Bayati 1990, Van Osdell et al. 1996, Kelly and Kinkead 1993). At least when only one VOC is present, data from tests of sorbents using high VOC concentrations can be used for approximate predictions of VOC removal efficiency and sorbent lifetime with more realistic lower inlet VOC concentrations (Liu 1990, Van Osdell et al. 1996, Axley 1994). The amount of carbon and the residence time for air are key determinants of sorbent system VOC removal performance (Muller 1993, Liu 1993) and systems with small amounts of carbon will be effective for only short periods (Muller 1993). Recommended residence times for the air in the sorbent bed are typically 0.1 to $0.2 \mathrm{~s}$ (Liu 1993). VOC removal efficiency and capacity can decrease with increased humidity and air temperature (e.g., Gong and Keener 1993). When the inlet air contains multiple VOCs, which is always the case in buildings, and a significant fraction of carbon is saturated with VOCs, a higher molecular weight VOC can drive a previously sorbed lower molecular weight VOC off a carbon sorbent bed, potentially causing the indoor VOC concentration to exceed that with no sorbent present (Liu 1993). Activated carbon, without any additives or impregnants, has a very low capacity for retention of some of the lower molecular weight polar compounds such as formaldehyde (Muller and England 1994, Tseng et al. 2005),

\footnotetext{
${ }^{6}$ There appears to be a mix-up in the numbering of packed bed filters in the published paper, thus, we did not consider data from the packed bed filters that contained all or part activated alumina.
} 
but chemisorbents can remove a few to several percent of their weight in formaldehyde (Muller and England 1994, product literature from various manufacturers). Consequently, a sorbent system that is effective in controlling indoor concentrations of the broad range of VOCs present indoors, as needed to enable reductions in outdoor air supply, will likely need to contain a physical sorbent and a chemisorbent.

\section{Field studies of VOC removal by sorbents deployed in commercial buildings}

In commercial buildings, sorbent systems will be faced with mixtures of at least a dozen important VOCs. Inlet VOC concentrations, air temperatures, relative humidity, and air flow rates will often vary over time. Little is known about the performance of sorbent systems under these conditions. In fact, the review identified only two studies with significant data on the VOC removal performance of sorbent systems installed in commercial buildings.

Weschler et al. (1992) installed panels filled with activated carbon in a test duct with a $0.61 \mathrm{~m}$ by $0.30 \mathrm{~m}$ (24 in by 12 in) cross section and measured VOC concentrations upstream and downstream of the activated carbon with passive samplers. The air entering the test duct was the air drawn from indoors, thus, the test duct simulated a real deployment. The test duct contained six $2.54 \mathrm{~cm}$ ( 1 in) thick carbon filled panels installed in a zig-zag pattern. The total panel face area was $2.0 \mathrm{~m}^{2}\left(22 \mathrm{ft}^{2}\right)$ and the total mass of activated carbon was $20.4 \mathrm{~kg}$ (45 lb). The air flow rate through the duct was $0.28 \mathrm{~m}^{3} / \mathrm{s}(600 \mathrm{cfm})$; thus, the nominal retention time in the carbon bed was $0.18 \mathrm{~s}$, well above the recommended minimum of $0.1 \mathrm{~s}$. The system contained $73 \mathrm{~kg}$ of carbon per $1 \mathrm{~m}^{3} / \mathrm{s}$ of airflow (75 lb per $1000 \mathrm{cfm}$ ). Table 1 provides average VOC removal efficiencies during the first 35 days of operation and efficiencies for some of the compounds measured after 18 months of continuous operation. Given the uncertainties in measurements of low VOC concentrations, $10 \%$ to $20 \%$ changes in measured efficiency are probably not significant; thus, Weschler's data indicate no drop in sorbent performance over an 18 month period of continuous operation.

Table 1. Results of long-term study of sorbent performance in a single building by Weschler et al. (1992)

\begin{tabular}{|c|c|c|}
\hline Compound & Initial Efficiency* & Efficiency after 18 months* \\
\hline Toluene & 0.9 & 0.9 \\
\hline Perchloroethylene & $\sim 1.0$ & $\mathrm{ND}$ \\
\hline Ethylbenzene & 0.7 & 0.9 \\
\hline m,p Xylene & 0.8 & 0.7 \\
\hline o-Xylene & 0.6 & $\mathrm{ND}$ \\
\hline Bromodecane & 0.8 & 0.9 \\
\hline 1,2,4-Trimethylbenzene & 0.7 & $\mathrm{ND}$ \\
\hline n-Decane \& $\mathrm{C}_{3}$-Alkylbenzene & 0.7 & $\mathrm{ND}$ \\
\hline Bromoundecane & 0.7 & 0.8 \\
\hline n-Undecane \& C $_{4}$-Alkylbenzene & 0.6 & $\mathrm{ND}$ \\
\hline n-Dodecane & 0.5 & \\
\hline
\end{tabular}

*based on numbers read from a graphical presentation \#ND = no data 
Bayer and Hendy (2005) studied the performance of sorbent systems installed in six commercial buildings using both periodic active short-term and passive long-term sampling methods. Removal efficiencies were measured for four VOCs - heptane, toluene, ethylbenzene, and formaldehyde. The sorbent system features (e.g., amount of sorbent, face velocities, residence times) were not described in detail. In three buildings, sorbent performance was tracked after installation of new sorbent media. Figure 3 shows a plot of efficiency versus time elapsed from sorbent installation based on the data collected using active VOC sampling ${ }^{7}$ in these three buildings. The results are inconsistent. Some data show expected declines in performance versus time with substantial pollutant removal efficiencies maintained for a half year or more. However, other data indicate that efficiency increased over time. Still other data indicate negative efficiency values indicating that the sorbent media became a pollutant source. According to the authors, an inability to measure the low VOC concentrations with sufficient accuracy was an important limitation - “ a majority of the detected concentrations were at or below the limits of quantitation". However, it is possible that the increases in efficiency over time and negative efficiencies were a consequence of one VOC driving another VOC off the activated carbon.

The results of the study by Bayer and Hendy (2005) illustrate the difficulties of evaluating sorbent system performance in uncontrolled filed studies. VOC concentrations can be low, leading to large measurement errors. In addition, periodic VOC measurements, which are the only type of measurements practical, yield an incomplete picture of sorbent system performance. It is possible that when sorbents are near the end of their service life, VOC removal efficiency could cycle between negative and positive values. Thus, a high VOC removal efficiency measured on one day - indicating the sorbent is still performing well - might have been preceded by an unmeasured poor or negative VOC removal efficiency on a prior day.

Based on these two studies, we cannot draw firm conclusions regarding the efficiency or lifetime of sorbent systems installed in field settings. The results of Weschler et al (1992) indicate that well-designed activated carbon systems will have a long life, exceeding 18 months. On the other hand, some of the results of the study by Bayer and Hendy (2005) suggest a much shorter service life for sorbent systems. However, measurement uncertainties and lack of full specifications raise significant questions about interpretation of results of the later study.

\footnotetext{
${ }^{7}$ The data from passive VOC sampling are more sparse and also do not provide a clear picture of sorbent performance over time.
} 

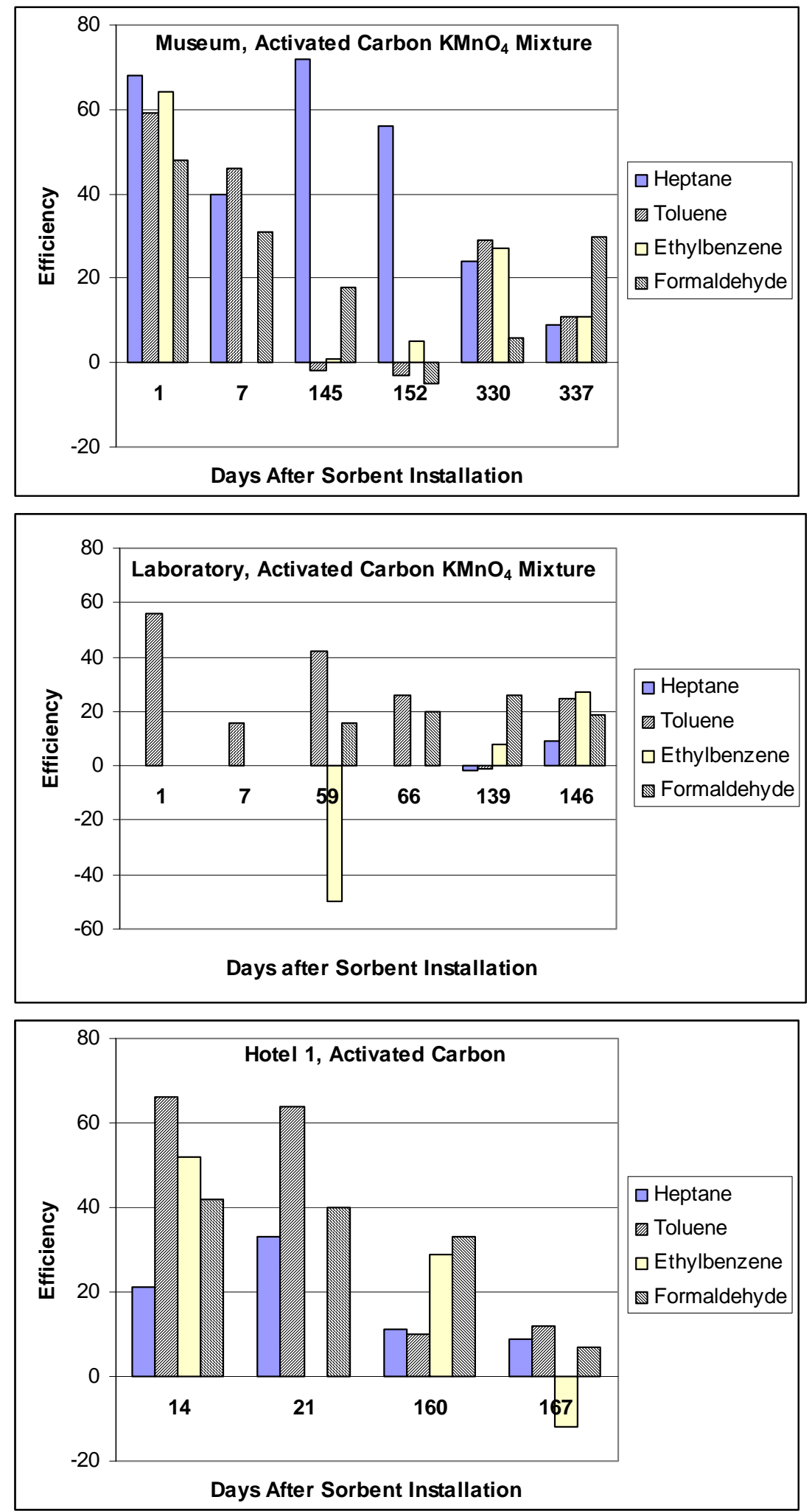

Figure 3. Sorbent performance versus time in three buildings by Bayer and Hendy (2005). 


\section{Cost Of Sorbent Systems}

There are large uncertainties regarding the life cycle costs of sorbent air cleaning due to the previously described uncertainties in sorbent service life. Nevertheless, a few papers have attempted to estimate costs.

Muller (1995) discusses the cost of using sorbents as a substitute for a portion of the outdoor air ventilation. He discusses three case studies, but provides detailed cost data for only one case. This is a medical center in Cincinnati initially supplied with $100 \%$ outdoor air from the HVAC system. A retrofit reduced the rate of outdoor air supply by $85 \%$ and substituted sorbent-based air cleaning in the same amount of recirculated indoor air. The HVAC system operated continuously. Table 2 presents the key cost and cost savings elements from the paper. Muller (1995) did not provide information on the minimum sorbent system efficiency or on the lifetime of sorbent media. Also, there were no VOC measurements. Thus, it is unknown if the air recirculation through the sorbent system resulted in equivalent or reduced indoor VOC concentrations as the unmodified building without air recirculation.

Henschel (1998) provided the most detailed identified analysis of the cost of an activated carbon sorbent system. In his hypothetical installation, the minimum required VOC removal efficiency was $70 \%$ with the goal of reducing indoor VOC concentrations by at least $85 \%$. He assumed no reduction in the rate of ventilation. The sorbent system operated 273 hours per month. He estimated that the activated carbon needed to be changed when it had sorbed $2 \%$ of its weight in VOC. Using an assumed typical indoor VOC source strength, the estimated carbon service life was 3.7 months. Key data on sorbent system costs as reported by Henschel (1998) are also provided in Table 2. Note that Henschel considered only the cost of an activated carbon sorbent system. Additional costs would be incurred if chemisorbent media were added to remove aldehydes from the supply air.

We have adjusted Henschel's cost data to address our goal of using the sorbent system to enable a reduction in the rate of outdoor air supply with no increase in indoor concentration of indoor generated VOCs. For every $1 \mathrm{~m}^{3} / \mathrm{s}$ reduction in outdoor air supply, the sorbent system would need to clean $1.42 \mathrm{~m}^{3} / \mathrm{s}$ of recirculated air with a minimum VOC removal efficiency of $70 \%$ $(1 / 0.70=1.42)$. Thus, by multiplying Henschel's costs by 1.42 , we can estimate the cost of sorbent air cleaning for each $1 \mathrm{~m}^{3} / \mathrm{s}$ or $1 \mathrm{cfm}$ reduction in outdoor air supply. These adjusted costs are also provided in Table 2.

The initial capital costs reported by Muller (1995) are twice those estimated by Henschel (1998). The annual sorbent media costs reported by Muller (1995) are 35\% higher than those reported by Henschel (1998), but Muller's sorbent system operated continuously while Henschel's sorbent system operated 37\% of the time. Multiplying Muller's annual sorbent media costs by 0.37 , yields $\$ 170$ per each $1 \mathrm{~m}^{3} / \mathrm{s}$ (\$0.081 per each $\mathrm{cfm}$ ) reduction in outdoor air supply, which is half of the cost estimated by Henschel. Despite the fact the Henschel's sorbent system operates 37\% of the time while Muller's system operates continuously, the information from Henschel (1998) lead to a $100 \%$ higher estimate of total annual recurring cost for sorbent air cleaning per unit flow of avoided outdoor air supply. 
To place the costs of sorbent air cleaning into perspective, data from Mudarri et al (1996) were used to estimate the energy costs of outdoor air ventilation for office, education, and public assembly buildings in three climates. These estimates are also provided in table 2.

In a new construction situation, an initial capital cost is incurred for the hardware associated with a sorbent system. In some buildings, a higher capacity and more expensive supply air fan may be needed to overcome the pressure drop of the sorbent media. However, if the outdoor air ventilation rate is reduced, there will be initial capital cost reductions because heating and cooling equipment can be downsized. No detailed estimate of the net effect of sorbent air cleaning on total capital costs was identified. One can; however, compare the estimates of total annual recurring costs for supplying a unit flow of air free of indoor generated VOCs via sorbent-based air cleaning and outdoor air ventilation. These annual recurring costs are highlighted in bold in Table 2 . The recurring costs of ventilation vary with climate while the recurring costs of sorbent air cleaning are largely independent of climate. Based on the estimates of recurring costs in Table 2, sorbent air cleaning appears economically attractive as a substitute for air cleaning. However, the uncertain lifetime of sorbent media make any such comparison very tentative.

\section{Sorbent regeneration}

Physical sorbents such as activated carbon that have become saturated with VOCs can be regenerated (EPA 1999), typically by use of steam to drive off previously sorbed contaminants. In this process, the sorbent temperature is usually raised to 120 to $180{ }^{\circ} \mathrm{C}$ ( 250 to $350{ }^{\circ} \mathrm{F}$ ). Vacuum systems can also be used to regenerate physical sorbents. After regeneration, activated carbon has about $50 \%$ of its initial capacity to hold contaminants. It is thought that the loss of capacity is a consequence of the lack of removal of VOCs from the smallest pores in the activated carbon (EPA 1999).

In general, regeneration is performed away from the site where the sorbent is used; however, methods of in-situ sorbent regeneration have received some evaluation. Rothman (1987) describes a process for in-situ sorbent regeneration using an inert gas such as heated nitrogen combined with heat recovery and cooling to condense out the pollutants removed from the sorbent. Smaller annual operating costs were predicted for this inert gas regeneration process than for traditional regeneration using using steam. Because considerable equipment is required, this regeneration process seems better suited for industrial applications than for use in typical buildings.

Knight et al (1993), as well as others, have analyzed the use of a rotary bed system with activated carbon media for in-situ sorbent regeneration. The system design is similar to that of rotary bed desiccants or rotary enthalpy heat recovery systems. A bed of activated carbon rotates slowly so that the carbon alternately sorbs pollutants from indoor air and then desorbs pollutants into a heated stream of outdoor air that is exhausted to outdoors. Seals minimize air leakage between the air supplied to the building and the heated regeneration airstream. Knight et al (1993) used models to evaluate the potential of rotary bed regeneration for building IAQ applications. In an 
Table 2. Estimated costs of sorbent air cleaning from two studies compared to estimated costs of ventilation in three climates*.

\begin{tabular}{|c|c|}
\hline \multicolumn{2}{|c|}{ Medical center in Cincinnati with continuous air cleaning and ventilation (Muller 1995) } \\
\hline \multicolumn{2}{|c|}{ Cost of sorbent air cleaning per unit reduction in flow rate of outdoor air supply ${ }^{+}$} \\
\hline Sorbent system initial cost excluding sorbent media & $\$ 2000$ per m³ $/ \mathrm{s} \quad(\$ 0.94$ per $\mathrm{cfm})$ \\
\hline Annual sorbent media and labor costs & $\$ 460$ per $\mathrm{m}^{3} / \mathrm{s} \quad(\$ 0.22$ per $\mathrm{cfm})$ \\
\hline Annual fan energy costs & $\$ 60$ per m $3 / \mathrm{s} \quad(\$ 0.029$ per $\mathrm{cfm})$ \\
\hline Total annual recurring costs (media, labor, fan energy) & $\$ 520$ per $\mathrm{m}^{3} / \mathrm{s} \quad(\$ 0.25$ per $\mathbf{~ f m})$ \\
\hline \multicolumn{2}{|l|}{ Energy cost savings } \\
\hline Heating and cooling & $\$ 7300$ per $\mathrm{m}^{3} / \mathrm{s}$ (\$3.46 per $\left.\mathrm{cfm}\right)$ \\
\hline Humidification & $\$ 1200$ per $\mathrm{m}^{3} / \mathrm{s}(\$ 0.58$ per $\mathrm{cfm})$ \\
\hline \multicolumn{2}{|c|}{ Hypothetical office building with air cleaning 273 hours per month (Henschel 1998) } \\
\hline \multicolumn{2}{|c|}{ Cost of sorbent air cleaning per unit flow rate of air cleaned with $\geq 70 \%$ efficiency } \\
\hline Installed hardware excluding sorbent media & $\$ 1000$ per m$^{3} / \mathrm{s} \quad(\$ 0.47$ per $\mathrm{cfm})$ \\
\hline Annual sorbent media costs including disposal & $\$ 340$ per m ${ }^{3} / \mathrm{s} \quad(\$ 0.16$ per $\mathrm{cfm})$ \\
\hline Annual cost of labor for media removal and replacement ${ }^{\#}$ & $\$ 320$ per m ${ }^{3} / \mathrm{s} \quad(\$ 0.15$ per $\mathrm{cfm})$ \\
\hline Total annual recurring costs for media and labor & $\$ 660$ per m ${ }^{3} / \mathrm{s} \quad(\$ 0.31$ per $\mathrm{cfm})$ \\
\hline Fan energy cost $\wedge$ & $\$ 95 \mathrm{per} \mathrm{m}^{3} / \mathrm{s} \quad(\$ 0.045$ per $\mathrm{cfm})$ \\
\hline \multicolumn{2}{|c|}{ Adjusted cost or cost per per unit reduction in flow rate of outdoor air supply ${ }^{* *}$} \\
\hline Installed hardware excluding sorbent media & 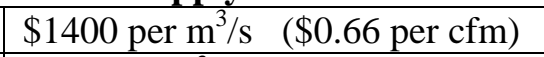 \\
\hline Annual sorbent media costs including disposal & $\$ 480$ per m $3 / \mathrm{s} \quad(\$ 0.23$ per $\mathrm{cfm})$ \\
\hline Annual cost of labor for media removal and replacement & $\$ 450$ per m ${ }^{3} / \mathrm{s} \quad(\$ 0.21$ per $\mathrm{cfm})$ \\
\hline Fan energy cost & $\$ 130$ per m³ $/ \mathrm{s} \quad(\$ 0.064$ per $\mathrm{cfm})$ \\
\hline Total annual recurring costs for media and labor & $\$ 1060$ per $\mathrm{m}^{3} / \mathrm{s} \quad(\$ 0.50$ per $\mathrm{cfm})$ \\
\hline \multicolumn{2}{|c|}{ Calculated energy costs of ventilation per unit flow rate of outdoor air (Mudarri et al. 1996) } \\
\hline Office bld. in Minneapolis ventilated $485 \mathrm{hr} /$ month & $\$ 1200$ per $\mathbf{m}^{3} / \mathrm{s}$ (\$0.55 per $\left.\mathbf{c f m}\right)$ \\
\hline Office building in Wash. D.C. ventilated $485 \mathrm{hr} /$ month & $\$ 1500$ per $\mathrm{m}^{3} / \mathrm{s}(\$ 0.70$ per $\mathbf{c f m})$ \\
\hline Office building in Miami ventilated $485 \mathrm{hr} /$ month & $\$ 2300$ per $\mathrm{m}^{3} / \mathrm{s}(\$ 1.10$ per $\mathbf{c f m})$ \\
\hline Education bld. in Minneapolis ventilated $264 \mathrm{hr} / \mathrm{month}$ & $\$ 2800$ per $\mathrm{m}^{3} / \mathrm{s}(\$ 1.33$ per $\mathbf{c f m})$ \\
\hline Education bld. in Wash. D.C. ventilated $264 \mathrm{hr} /$ month & $\$ 2300$ per $\mathrm{m}^{3} / \mathrm{s}$ (\$1.07 per $\left.\mathbf{c f m}\right)$ \\
\hline Education building in Miami ventilated $264 \mathrm{hr} / \mathrm{month}$ & $\$ 1400$ per m $~_{3}^{3}$ s (\$0.64 per $\left.\mathbf{c f m}\right)$ \\
\hline Public assembly bld. in Minneapolis ventilated $485 \mathrm{hr} / \mathrm{month}$ & $\$ 4500$ per $\mathrm{m}^{3} / \mathrm{s}$ (\$2.13 per $\left.\mathrm{cfm}\right)$ \\
\hline Public assembly bld. in Wash. D.C. ventilated 485 hr/ month & $\$ 3300$ per $\mathrm{m}^{3} / \mathrm{s}$ (\$1.54 per $\left.\mathbf{c f m}\right)$ \\
\hline Public assembly bld. in Miami ventilated $485 \mathrm{hr} / \mathrm{month}$ & $\$ 1900$ per $\mathrm{m}^{3} / \mathrm{s}$ (\$0.91 per $\left.\mathbf{c f m}\right)$ \\
\hline
\end{tabular}

*All costs were escalated for inflation to yield estimated costs in 2004. Energy costs were escalated using the consumer price index for energy (Census Bureau 2006). Costs of equipment and labor were escalated using the consumer price index for all products except food and energy (Census Bureau 2006).

${ }^{+}$It is unknown whether concentrations of indoor generated VOCs were unchanged.

\# Cost of $6.5 \mathrm{hr}$ of labor at $\$ 49.48$ per hour for labor (Means 2005), based on Henchel's estimate of two hours of labor to remove and replace sorbent media for a system cleaning $1 \mathrm{~m}^{3} / \mathrm{s}(2120 \mathrm{cfm})$ of air and a sorbent media change every 3.7 months

$\wedge$ Estimated from standard fan laws using the pressure drop across the sorbent media of $250 \mathrm{~Pa}\left(1\right.$ inch $\left.\mathrm{H}_{2} 0\right)$ from Henschel (1998), a typical fan motor efficiency of 0.9 , a typical fan efficiency of 0.75 , and an electricity price in 2004 for commercial buildings of \$0.079 per KWh (DOE 2005)

**Adjusted as described in text to estimate cost per unit flow reduction in outdoor air supply 
example calculation, to clean $1.4 \mathrm{~m}^{3} / \mathrm{s}(3000 \mathrm{cfm})$ the model called for a rotary bed $0.15 \mathrm{~m}(0.5$ $\mathrm{ft})$ thick and $0.95 \mathrm{~m}(3.1 \mathrm{ft})$ in diameter with a regeneration air temperature of $60{ }^{\circ} \mathrm{C}\left(140{ }^{\circ} \mathrm{F}\right)$. Knight et al (1993) concluded that a rotary bed system has the potential to be practical; however, the paper did not present cost analyses. In a rotary system, one would have initial equipment costs, maintenance costs, costs of energy for heating the regeneration airstream, and additional space cooling costs because some heat is transferred to the indoor air from the regeneration system.

Periodic in-situ sorbent regeneration has also been considered. For example, a sorbent system could be regenerated each night using heated or unheated outdoor air. For a hypothetical airport application where the main source of VOC is polluted outdoor air, Axley (1994) predicted that a sorbent system with $0.5 \mathrm{~mm}$ diameter grains of activated carbon and with an eight-hour night purge with unheated outdoor air would reduce indoor time average VOC concentrations by approximately 25\%. Peak indoor VOC concentrations were not reduced by the sorbent system. Axley (1994) also modeled a system with an eight-hour night purge of the sorbent using air heated to $50{ }^{\circ} \mathrm{C}\left(120{ }^{\circ} \mathrm{F}\right)$. In this case, the predicted indoor concentration was reduced by more than half. No economic analysis was presented.

Liu (1992) conducted experiments in a laboratory to study nighttime in-situ regeneration of activated carbon using unheated outdoor air as the regeneration air stream. Toluene at high concentrations (40 ppm) was employed as the test compound. The desorption process was found to be too slow to be practical if the sorbent media was $4 \mathrm{X} 8$ mesh granular activated carbon with a typical grain size of $3.5 \mathrm{~mm}$ (0.14 inch). However, sorbent regeneration occurred much more quickly using an activated carbon fiber sorbent that has an average fiber diameter of $0.015 \mathrm{~mm}$ (0.0006 inch). Two hours of purging at face velocity of $0.25 \mathrm{~m} / \mathrm{s}$ (50 fpm) using clean air with $50 \%$ relative humidity removed $65 \%$ of the previously sorbed toluene from a $4 \mathrm{~mm}(0.16$ inch) thick the activated carbon fiber bed. Liu (1992) then studied nighttime regeneration of a fullscale activated carbon fiber adsorption unit system for ten regeneration cycles. Air temperature during sixteen-hour desorption cycles was 7 to $18{ }^{\circ} \mathrm{C}\left(45\right.$ to $\left.65{ }^{\circ} \mathrm{F}\right)$ and relative humidity was $50 \%$ to $80 \%$. The face velocity of air entering the sorbent was typically $0.5 \mathrm{~m} / \mathrm{s}$ (100 fpm) during regeneration. $85 \%$ to $95 \%$ of the previously sorbed test compound (toluene) was driven off the carbon fiber bed during desorption cycles. During the eight-hour periods of simulated air cleaning, inlet toluene concentrations ranged from 0.13 to $5.3 \mathrm{ppm}$ and the face velocity of air entering the sorbent was $2.5 \mathrm{~m} / \mathrm{s}(500 \mathrm{fpm})$, which is typical of a particle filter system. The toluene removal efficiency during the simulated cycles of air cleaning ranged from $20 \%$ to $90 \%$, which is adequate to offset the VOC concentration increases expected from a $50 \%$ reduction on outdoor air supply. These results suggest that an activated carbon fiber system with night-time regeneration using unheated air is promising. A supplemental system with chemosorbents that could not be regenerated would be needed to remove VOCs not readily sorbed by activated carbon.

\section{NOVEL SORBENT PRODUCTS}

Several novel sorbent-based products for gas-phase air cleaning have been or are being evaluated. This section briefly describes these products, although none appear likely to fill 
DOE's near-term need for a gas-phase air cleaning system to enable reduced ventilation rates in commercial buildings.

Yu and Neretnieks (1993) and Yu et al (1993) modeled indoor VOC concentrations in a $48 \mathrm{~m}^{3}$ $\left(1700 \mathrm{ft}^{3}\right)$ room with and without installation of a "passive adsortion sheet" containing granular activated carbon. The sheet was placed in the room and air and VOC transport to the sheet occurred via natural airflows and diffusion. The passive adsorption sheets were $10 \mathrm{~m}^{2}\left(108 \mathrm{ft}^{2}\right)$ in area and $2 \mathrm{~mm}$ (0.08 inch) thick. Based on information provided, different versions of the passive adsorption sheet contained 1.6 and $9.6 \mathrm{~kg}$ (3.5 and $21.2 \mathrm{lb}$ ) of carbon. The predictions, which considered only one or two VOCs, indicated substantial reductions in indoor VOC concentrations for periods exceeding one year. The prediction of long-term VOC concentration reductions with a system containing so little sorbent is surprising and needs to be verified by further research.

Rohrback et al (1996) presented results of laboratory tests of a "wicking fiber" chemisorption system. The air cleaner uses polypropylene fibers with the cross section illustrated in Figure 4 and a diameter of 32 micrometers. A liquid chemisorbent media is "captured by the fiber and retained through capillary action." The fiber can hold more than its weight in active reagents, and coated fibers present a very large surface are. The fibers can reportedly be made into woven and non-woven mats and used in a form typical of a pleated particle filter. In the laboratory, a filter made of these fibers was used to remove hydrogen sulfide, sulfur dioxide, and acetaldehyde from an airstream. Chemically treated activated carbon was used in the same tests. The wicking fiber filters had higher pollutant removal efficiency, greater capacity, and lower airstream pressure drop than the activated carbon. Based on this one paper, the technology appears promising, although no information on costs were presented. No subsequent papers on the same technology were identified and attempts to contact the two lead authors were unsuccessful.

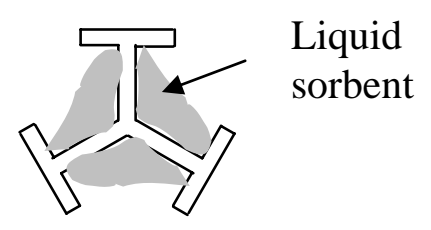

Figure 4. Approximate illustration of the cross section of the 32 micrometer diameter wicking fibers used by Rohrbach et al. (1996).

Another novel sorbent product is a gas absorption membrane absorber (van der Wal et al. 1993). The system contains hollow fiber membrane modules with a geometry similar to that in a shell and tube heat exchanger, as depicted in Figure 5. Air flows through the hollow central tubes 0.24 to $1.8 \mathrm{~mm}$ ( 0.01 to 0.07 inch) in diameter located inside a larger tube through which a liquid absorbent flows. Pollutants pass through the semi-permeable wall of the inner tubes into the absorbent. The system provides a very large surface area and the ability to store and continuously replenish a large mass of absorbent. In proof of concept tests, some water soluble pollutants were removed efficiently using water as the absorbent. However, the reported airstream pressure drops were 100 to $3000 \mathrm{~Pa}$ (0.4 to 12 inch of water). Only pressure drops at 
the low end of this range are potentially acceptable in an HVAC system. Tan et al (2005) investigated a very similar technology with different types of fibers. Modeling and experimental data served as a proof of concept. They discussed the potential to use such a system with water condensed out of air by the air conditioner as the solution to remove water-soluble indoor pollutants. No information on costs was presented in either paper.

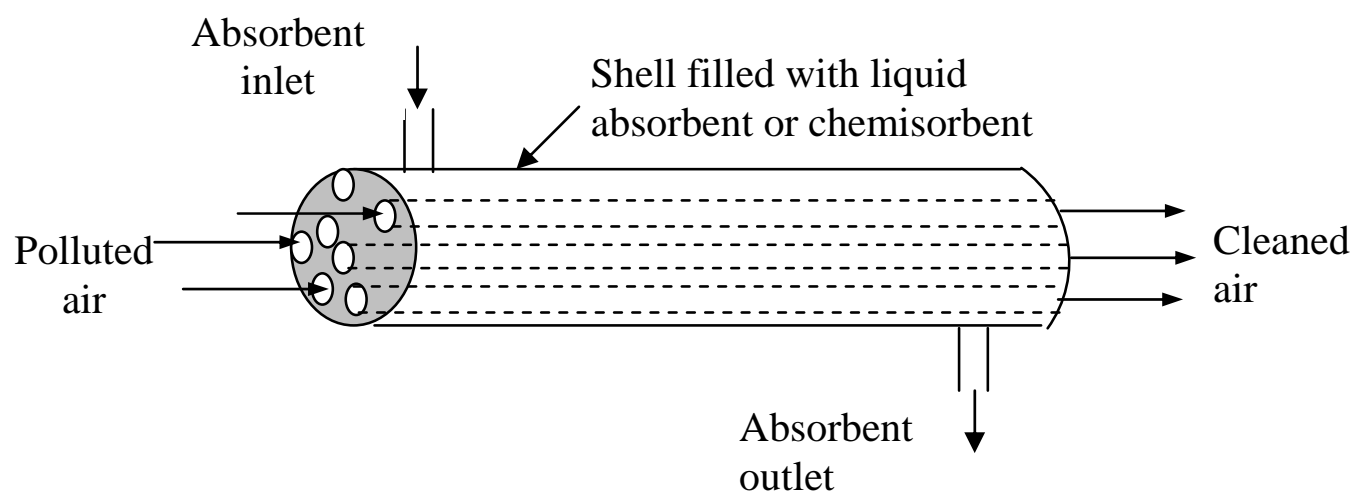

Figure 5. Illustration of hollow fiber membrane modules tested by van der Wal et al. (1993)

Law et al. (2004) investigated the use of a synthetic zeolite sorbent in combination with upstream oxidant generating devices, i.e., an ozone generator or ionizer that produces reactive oxygen species. The goal was to have oxidation reactions occur on the surface of the sorbent to consume some of the sorbed VOCs and extend the lifetime and improve the efficiency of the sorbent. Their data indicate that the zeolite can adsorb the oxidant, which is necessary for surface based reactions. In addition, the combination of the oxidant generator and zeolite removed acetone and ammonia more effectively than either technology alone. Using the ozone generator, but not the ionizer, increased the concentrations of ozone downstream of the zeolite sorbent. The study did not determine if undesirable products were produced from incomplete VOC destruction.

Coss and Cha (2000) investigated the use of a microwave system for regeneration of activated carbon and briefly discussed prior tests of microwaves as a means to regenerate activated alumina and zeolite sorbents. The results of pilot tests of this regeneration method were promising. It is notable that activated carbon regenerated in this manner had nearly the same capacity as virgin carbon media, while the more traditional steam-based regeneration has been shown to result in substantially reduced capacity (EPA 1999).

\section{KEY RESEARCH NEEDS}

While one could develop a long list of research needs pertaining to sorbent based air cleaning for VOCs in buildings, the following four areas of research are suggested as the highest priorities for the U.S. DOE and other energy agencies given the need for an air cleaning technology usable in the next few years in a wide range of commercial buildings. 
As the highest priority, we suggest research to better define VOC removal efficiencies and the useful lifetime of sorbents for commercial building applications, keeping in mind that commercial buildings have many VOCs present at low and time-varying concentrations. This research should evaluate advanced sorbent systems that contain both a physical adsorbent, such as activated carbon for removal of higher molecular weight non-polar compounds, and a chemisorbent for removal of lower molecular weight compounds like formaldehyde. The main concern is the lifetime of the physical adsorbent.

An approach for this highest priority research is also suggested. Ideally, one would deploy sorbent systems in buildings and monitor inlet and outlet concentrations of dozens of VOCs continuously for several months to assess sorbent lifetime; however, such a study is prohibitively expensive. Only periodic measurements of VOCs are practical and such measurements will not yield unambiguous information on sorbent performance in an uncontrolled field setting where a sorbent might work well under one set of condition, but perform poorly under different unmeasured conditions. Consequently, we suggest measuring performance of multiple sorbent systems over a several month period in a laboratory setting where the sorbents are challenged with synthetic mixtures of VOCs with constituents and concentrations representative of those in buildings. During most periods, inlet VOC concentrations and air RH and temperature would be maintained constant. However, intentional spikes and dips in VOC concentrations, air temperature, and humidity, with simultaneous VOC sampling would determine if the sorbent system still has enough capacity to perform well under such transient conditions, which should be typical of transient conditions encountered in real buildings.

Research on in-situ regeneration of activated carbon using unheated outdoor air is also suggested as a high priority. If this process is effective, it would be much more practical and energy efficient than in-situ regeneration using heated air. Also, effective in-situ generation would reduce the expenditures needed on sorbent media replacement. The research would initially test the efficacy of in-situ regeneration in a laboratory setting, again with sorbents challenged with synthetic mixtures of VOCs with constituents and concentrations representative of those in buildings. The test protocol would again include intentional spikes and dips in VOC concentrations, air temperature, and humidity, with simultaneous VOC sampling to determine if the sorbent system still has enough capacity to perform well under such transient conditions. Based on the research of Liu (1992), carbon fiber systems should be included in this research. Unlike the research of Liu (1992), the proposed study would evaluate sorbent performance for a broad range of VOCs encountered indoors.

An updated analysis of the cost of sorbent air cleaning, accounting for the new data on sorbent VOC removal performance and lifetime is a third suggest priority area of research.

Finally, as a fourth priority we suggest use of the new data from sorbent performance testing in conjunction with existing information on odor thresholds, irritancy thresholds and potencies, and toxicity of VOCs to determine if sorbents satisfy the aforementioned criteria for systems that can counteract the VOC concentration increases from decreased building ventilation. 


\section{CONCLUSIONS}

The major conclusions from this review are as follows:

- Considering the types of pollutants typically emitted inside commercial buildings, simultaneous air cleaning for particles and VOCs, using air cleaning systems with moderate pollutant removal efficiencies in the supply or return airstreams of HVAC systems, may enable reduced ventilation rates without a degradation of indoor air quality.

- Sorbent systems can remove a broad range of VOCs with moderate to high efficiency.

- Sorbent technologies perform effectively when challenged with the low VOC concentrations present indoors.

- There is a large uncertainty about the lifetime of sorbent air cleaning for VOCs when used in commercial buildings.

- Based on the estimates of recurring costs, sorbent air cleaning appears economically attractive as a substitute for ventilation. However, such comparisons are tentative due to the uncertainties regarding the lifetime of sorbent media.

- Research to better define sorbent system VOC removal efficiencies and lifetimes under conditions representative of those in commercial buildings is suggested as the highest priority.

\section{ACKNOWLEDMENTS}

This work was supported by the Assistant Secretary for Energy Efficiency and Renewable Energy, Building Technologies Program of the U.S. Department of Energy under contract DEAC02-05CH11231. The author thanks Henrik Wallman and Al Hodgson for reviews of a draft of this paper.

\section{REFERENCES}

Axley JW (1994) Tools for the analysis of gas phase air cleaning systems in buildings. ASHRAE Transactions 100(2): 1130 - 1146

Bayer CW and Hendry RJ (2005) Field test methods to measure contaminant removal effectiveness of gas phase air filtration equipment - phase 2. ASHRAE Transactions 111(2).

Cal-EPA. 2002. Air Toxics “Hot Spots” Program Risk Assessment Guidelines. Part III. Technical Support Document for the Determination of Chronic Reference Exposures Levels for Airborne Toxicants. Office of Environmental Health Hazard Assessment, Air Toxicology and Epidemiology Section, California Environmental Protection Agency, Berkeley, CA. Cal-EPA Air Toxics Hot Spots web site: http://www.oehha.org/air.html

Census Bureau (2006) Statistical Abstract of the United States: 2006. U.S. Census Bureau. Washington, D.C. 
Coss PM and Cha CY (2000) Microwave regeneration of activated carbon used for removal of solvents from vented air. Journal of the Air \& Waste Management Association 50: 529-535.

DOE (2005) Building Energy Databook-2005. U.S. Department of Energy, Washington, D.C.

EPA (1999) Technical bulletin: choosing an adsorption system for VOC: carbon, zeolite, or polymers? U.S. Environmental Protection Agency Report 456/F-99-004, Clean Air Technology Center, Research Triangle Park, NC.

Gong R and Keener TC (1993) A qualitative analysis of the effects of water vapor on multicomponent vapor phase carbon adsorption. Journal of the Air and Waste Management Association 43: $864-872$.

Graham JR and Bayati MA (1990) The use of activated carbon for the removal of trace organics in the control if indoor air quality. Proceedings of Indoor Air 90, vol. 3, pp $133-138$. International Conference on Indoor Air Quality and Climate, Inc., Ottawa, Ontario.

Gundel, L.A.; Sullivan, D.P.; Katsapov, G.Y.; Fisk, W.J. (2002) A pilot study of energy efficient air cleaning for ozone. Lawrence Berkeley National Laboratory Report, LBNL-51836, Berkeley, CA.

Henschel B (1988) Cost analysis of activated carbon versus photocatalytic oxidation for removing organic compounds from indoor air. Journal of the Air \& Waste Management Association 48: 985-994.

Hodgson AT, and Levin H (2003) Classification of measured indoor volatile organic compounds based on non-cancer health and comfort considerations. Lawrence Berkeley National Laboratory Report, LBNL-53308, Berkeley, CA.

Hodgson AT, Sullivan DP, Fisk WJ (2005) Evaluation of ultra-violet photocatalytic oxidation (UVPCO) for indoor air applications: conversion of volatile organic compounds at low part-perbillion concentrations. Lawrence Berkeley National Laboratory Report, LBNL-58936, Berkeley, CA.

Kelley TJ, and Kinkead DA (1993) Testing of chemically treated adsorbent air purifiers. ASHRAE Journal July 1993, pp $14-23$.

Kinkead DA (1990) Pleated dry processed carbon-composite (DPCC) based adsorbers, an inescapable new technology for HVAC air purification. Proceedings of Indoor Air 90, vol 3, pp 139-144. International Conference on Indoor Air Quality and Climate, Inc., Ottawa, Ontario.

Knight KM, Klein SA, and Mitchell JW (1993) Analysis of a rotary adsorbent filter for indoor air quality control. ASHRAE Transactions 99(1): 811 - 824.

Law TSC, Chao CYH, Chan GYW, and Law AKY (2004) The use of zeolite and oxidant generating devices in air cleaning. Indoor and Built Environment 13: 45-51. 
Liu RT (1990) Removal of volatile organic compounds in IAQ concentrations with short carbon bed depths. Proceedings of Indoor Air 90, vol. 3., pp. 177 - 182. International Conference on Indoor Air Quality and Climate, Inc., Ottawa, Ontario.

Liu RT (1992) An in-situ regenerative adsorber for the control of indoor VOCs - activated carbon fibers. Proceedings of IAQ’92, pp. 257 - 261. ASHRAE, Atlanta.

Liu RT (1993) Use of activated carbon adsorbers in HVAC applications. Proceedings of the IAQ’93 Conference, pp 209-217. American Society of Heating, Refrigerating, and Air Conditioning Engineers, Atlanta.

Means (2005) Means mechanical cost data. R.S. Means, Kingston, MA.

Middlebrooks MC (2000) Benefits of non-woven structure on adsorption performance of novel filter medium. Proceedings of Techtextil North American Symposium, Atlanta, GA.

Mudarri D, Hall JD, and Werling E (1996) Energy cost and IAQ performance of ventilation systems and controls. Proceedings of IAQ’96, pp. 151- 160. ASHRAE, Atlanta.

Muller CO and Middlebrooks MC (2001) Application and evaluation of a new dry-scrubbing chemical filtration media. Paper 42, Proceedings of the Air \& Waste Management Association $94^{\text {th }}$ Annual Meeting and Exhibition, June 24-28, Orlando, CA

Muller CO (1993) Packed bed vs. carbon-impregnated fiber gas-phase air filters for the maintenance of acceptable IAQ. Proceeding of IAQ'93. pp. 219 - 235. ASHRAE, Atlanta.

Muller CO and England WG (1994) Gas phase air filtration: single medium or multiple media systems - which should be used for IAQ applications. Proceedings of IAQ’94, pp 157 - 168. ASHRAE, Atlanta.

Muller CO (1995) Improving building IAQ reduces HVAC energy cost. Proceedings of the $2^{\text {nd }}$ International Conference on Indoor Air Quality, Ventilation, and Energy Consumption in Buildings. Montreal, Canada.

Rohrbach R, Unger P, Bause D, Xue L, Williams R, Dondero R, Leyrer L, Jones G (1996) Wicking fiber chemisorption for air quality improvement. Proceedings of IAQ’96, pp. 61 - 66, ASHRAE, Atlanta.

Rothman HV (1987) Air pollution control using an inert gas regenerated carbon bed. ASHRAE Transactions: 93(1): 651-656.

Tan X, Li K, Teo WK (2005) Odor control using hollow fiber membrane modules. American Institute of Chemical Engineers Journal 51(5): 1367-1376. 
Tseng CH, Hsieh CD, and Chen SS (2005) The removal of indoor formaldehyde by various air cleaners. Paper 457, Proceedings of the Air \& Waste Management Association's 98 ${ }^{\text {th }}$ Annual Conference, Minneapolis, Minnesota.

U.S. EPA. (2000) National air toxics program: the integrated urban strategy report to Congress. Office of Air Quality Planning and Standards, U.S. Environmental Protection Agency, Research Triangle Park, NC. U.S. EPA Air Toxics web site: http://www.epa.gov/ttn/atw/index.html

VanOsdell DW, Owen MK, Jaffe LB, and Sparks LE (1996) VOC removal at low contaminant concentrations using granular activated carbon. Journal of the Air \& Waste Management Association 46: 883 - 890.

Van der Wal JF, Klaassen R, Moons AMM, and Walpot JI (1993) Development of an air cleaner based on gas absorption membranes. Indoor Air 3: 322-327.

Weschler CJ, Shields HC, and Naik DV (1992) An evaluation of activated carbon filters for the control of ozone, sulfur dioxide, and selected volatile organic compounds. Proceedings of IAQ’92, pp. 233 - 241. ASHRAE, Atlanta.

Wolkoff P, Wilkins CK, Clausen PA, and Nielsen GD (2006) Organic compounds in office environments - sensory irritation, odor, measurements and the role of reactive chemistry. Indoor Air 16: 7-19.

Yu J-W, and Neretnieks I (1993) The effect of a passive adsorption sheet on reducing organic pollutants in indoor air. Indoor Air 3:12-19.

Yu J-W, Christiansson J, and Neretnieks I (1993) Modeling of a passive adsorption sheet to purify indoor air. Indoor Air 3: 310 - 314. 